\title{
As especificidades da formação de professores da educação profissional
}

\section{The specificities of teacher training in the context of professional education}

\author{
Alfredo Bravo Marques Pinheiro, Maria Deuceny da Silva Lopes Bravo Pinheiro, Carlos Manuel Folgado Barreira, \\ Maria da Piedade Vaz Rebelo \\ Faculdade de Psicologia e Ciências da Educação da Universidade de Coimbra
}

\begin{abstract}
Resumo
A presente comunicação objetiva apresentar uma abordagem dos modelos de formação de professores e das propostas de desenvolvimento profissional defendidas por diversos autores. Apresenta uma retrospectiva da expansão da educação profissional e tecnológica, seus reflexos nas políticas públicas na legislação brasileira de preparação de docentes para lecionar em cursos técnicos e tecnológicos e influências advindas da interligação com a indústria brasileira. As questões pedagógicas e o preparo dos professores da educação técnica/tecnológica passaram por modificações dando maior peso aos interesses das políticas governamentais, aos interesses dos estabelecimentos de ensino e relegando para segundo plano as dimensões dos docentes.

Palavras-chave: Formação de Professores, Educação Profissional, Políticas públicas.
\end{abstract}

\begin{abstract}
This study present an approach to teacher training models and the professional development proposals defended by various authors. It presents a retrospective of the expansion, its reflexes in the public policies in the Brazilian legislation of preparation of teachers to teach in technical and technological courses of professional and technological education and influences arising from the interconnection with Brazilian industry. The pedagogical questions and the preparation of the teachers of the technical / technological education have changed giving greater weight to the interests of government policies, to the interests of educational establishments and forgetting the dimensions of the teachers.
\end{abstract}

Keywords: Teacher Training, Professional Education, Public Policies

\section{Modelos de desenvolvimento profissional}

A gama de artigos escritos sobre o desenvolvimento profissional faria estender-nos sobre o assunto, mas o que parece mais comum é a justaposição de conceitos que envolvem a matéria. De um lado, o entendimento de desenvolvimento profissional do professor como docente (Sikes, 1985; Huberman, 1992), que pretende crescer na carreira enquanto profissional, igualmente a qualquer outro que tem intenção de progredir enquanto especialista em seu assunto e, por outro lado, o desenvolvimento com a visão da dimensão da profissionalidade do professor, da dimensão do indivíduo, da cognitiva, da identidade, da ética, das concepções e dos saberes profissionais (Kugel,1993; Robertson 1999).

Dentre as diversas propostas existentes, a de desenvolvimento profissional dos professores com conceito de crescimento na carreira apresentada por Zabalza (2007) induz à percepção da concomitância entre o processo e o percurso de carreira apresentados por Unruh e Turner, Katz e Gregorc nos anos de 1970; Feinian e Floclen, Sikes, Burke e Alii, Vomk e Huberman nos anos de 1980; passando por Bolam, Leithwood, Gonçalves e Fessles nos anos de 1990, Formosinho no ano de 2000 e Garcia em 2009. Unruh e Turner em 1970, apresentaram seu modelo de desenvolvimento, distinguindo em três fases: período inicial, compreendendo de 1-5 anos; a de construção da segurança, incidindo de 6-15 anos e a da maturidade, contemplando mais de 15 anos. Por sua vez, Katz em 1972 viu o seu modelo caracterizado em quatro fases sendo o da sobrevivência (de 1 a 2 anos); de consolidação (no ano 3); da renovação (no ano 4) e da maturidade (após o ano 5). Gregorc em 1973 designou suas etapas de desenvolvimento como: início, crescimento, maturidade e plenitude e Feinlan e Floclen em 1983, de sobrevivência, consolidação, renovação e maturidade. Bolan em 1990 dividiu em cinco etapas seu modelo de desenvolvimento: preparatório, adaptação, socialização, de exercício profissional e de transição.

Com modelo de desenvolvimento profissional centrado nos cinco ciclos de vida do professor, em 1985 Sikes (1992) estabeleceu período de idades para cada uma das etapas por ele concebidas: a da entrada na carreira, entre 21 a 28 anos que corresponde ao fim da formação inicial; a da transição entre 28 e 33 anos, quando a vida pessoal passa por muitas modificações; a da maturidade entre 33 e 40 anos, onde já passa a ser considerado experiente; o do não exercício das funções docentes entre 40 e 55 anos, quando passam a exercer outras funções, diminuindo o tempo em sala de aula; e, a última, aquela próxima à aposentadoria, onde as preocupações com o avanço da carreira já não se fazem mais presentes e a preocupação passa a ser maior com o aprendizado dos alunos.

Com características diferentes, Huberman (1989, 1992) também idealizou seu modelo de desenvolvimento profissional em cinco etapas, coincidente em termos de tempo, mas não em idade dos professores e sim no período de atuação na profissão de docente. São elas: fase de adaptação, coincidente com o início da carreira, indo até o terceiro ano; fase de estabilização, onde já há certa estabilidade na carreira, incidindo do quarto ao sexto ano; o de experimentação e reenquadramento, onde o questionamento de sua carreira passa a existir, indo dos 7 aos 25 anos de 
profissão; fase da serenidade e distanciamento afetivo onde já não há mais tanta preocupação com o crescimento funcional, indo de 25 aos 35 anos de carreira; e a fase do desinvestimento onde a preocupação com a aposentadoria torna-se evidente, coincidente entre 35 a 40 anos de atividade profissional. Embora elogiado por Day (2001), por apresentar um estudo significativo sobre a carreira do professor, este alerta para a existência de lapso entre os níveis de desenvolvimento e as necessidades docentes.

Se compararmos os modelos de Sikes e Huberman, pode-se verificar que a ideia é a mesma, com perspectivas diferentes, indicando o fator tempo com principal cunho do processo. A primeira etapa apresentada por Sikes (1992), a entrada na carreira que se dá, normalmente, dos 21 aos 28 anos coincidindo com o término da graduação, ou seja, início da vida docente é o mesmo conceito aplicado por Huberman (1992) que o nomeia do primeiro ao terceiro ano de profissional. Assim se sucedem as etapas até a última fase, quando Sikes (1992) a nomeia

"próxima da aposentadoria" e este o de "desinvestimento".

O modelo apresentado por Leithwood (1990) se baseou, em sua essência, nos modelos de Sikes (1992) e Huberman (1992), seus precursores, unindo as dimensões profissional, psicológica e da carreira: as fases do início da carreira, da estabilização, dos desafios, da plataforma profissional e do preparo da jubilação. Já o modelo de Steffy, Wolfe, Pash e Enz (2000) também estabelece fases, assim como os anteriores e dentro de uma cronologia similar, atribuindo conceitos fundamentais de reflexão e capacidade de decisão como fatores de desenvolvimento dos professores. São denominadas de: professor principiante, na primeira fase; professor aprendiz na segunda; na terceira fase, professor especialista; a quarta fase, onde a maioria dos professores encerra sua carreira, professor distinto e na quinta e última fase, professor jubilado.

Garcia (1999) e Formosinho (1999) com base no modelo de Sparks e Loucks-Horsley (1990) que entende que o desenvolvimento profissional dos professores suscita uma amplitude de dimensões abrangendo o desenvolvimento pedagógico, o desenvolvimento do conhecimento e compreensão de si mesmo, o desenvolvimento cognitivo, o desenvolvimento teórico tendo a reflexão da prática docente como base, o desenvolvimento profissional via investigação e o desenvolvimento da carreira, por meio de atribuições inovadoras dos professores. Nomeando esses ciclos como: reflexivo quando os professores pensam a respeito das próprias práticas permitindo terem desenvolvimento mais sustentado e consciente e observa o comportamento de seus pares; autônomo, quando os docentes passam a conquistar de per si conhecimentos novos, através de leitura de livros, revistas, artigos e desenvolvem competências baseadas em suas próprias experiências e é preferida pois entendem que as formações disponíveis não atendem suas necessidades; investigativo, quando os docentes ficam envolvidos em investigações sobre as suas próprias práticas e em processos de reflexão; formativo, os docentes acompanham cursos de formação e tem o intuito de que apreendam os conteúdos na formação e que os utilizem em sala de aula; e curricular, onde os docentes descobrem e logram aprimorar suas práticas a partir do momento que vêm resolvidos problemas relacionados ao seu trabalho, envolvendo-se em projetos curriculares.

A concepção de desenvolvimento profissional a partir das funções docentes, pode ser entendida dentro dos modelos idealizados por Kugel(1993), que dividiu em uma fase que dá ênfase ao ensino e outra que privilegia a aprendizagem, e o de Robertson (1999), que classificou também em fases de ensino e aprendizagem, mas acrescentando uma outra que, compreendendo aspectos das duas anteriores, tem uma visão de um sistema dinâmico.

Esses modelos de desenvolvimento profissional demonstram a similaridade de ideias, com enfoques diferentes em termos de peculiaridade em relação ao conceito de onde começa a formação profissional: se na fase de início de carreira ou na fase inicial de formação antes do início como docente, o que nos permite compreender o processo evolutivo da carreira docente nas últimas décadas e refletir sobre o processo histórico da formação profissional e as lacunas existentes na formação de professores, principalmente para a educação profissional, que historicamente esteve diretamente envolvida com o desenvolvimento da indústria brasileira.

\section{A indústria e a formação profissional no Brasil}

Premidos pelas necessidades industriais brasileiras, até por que, à época de 1909, apenas engatinhava, a criação das Escolas de Aprendizes Artífices, pelo governo brasileiro, teve um cunho muito voltado para as questões sociais porquanto mantinha $o$ foco no entendimento que era preciso prover os necessitados de oportunidades que os levasse ao próprio sustento, além de diminuir a possibilidade do cometimento de delitos por parte dos potencialmente desocupados. $\mathrm{Na}$ realidade, já no final do século XIX, os lucros dos grandes produtores de café brasileiro começaram ser direcionados para as indústrias localizadas no Rio de Janeiro e São Paulo, indústrias estas de produtos primários, de fácil elaboração, como tecidos e calçados e que demandavam mão-de-obra sem muita especialização para seu pleno funcionamento.

Com o passar dos anos e durante muitos deles, a industrialização brasileira seguiu em compasso de espera, com produção de bens primários, influenciada pela Revolução de 1930 e marcada que foi pelo impacto da depressão mundial causada pela crise americana de 1929 (Furtado, 1997) com a quebra da bolsa de Nova York. Somente no primeiro governo do Presidente Getúlio Vargas, no final da década de 1930 e início da de 40, a indústria começou a se desenvolver, tendo como mote principal a ideia de que o Brasil não poderia ser mais dependente de produtos importados, uma vez que já se encontrava parcialmente livre da pressão inglesa, até àquela época dominadora e então comprometida com os conflitos na Europa, no 
desenrolar da segunda grande guerra, criaram-se condições favoráveis para o desenvolvimento da indústria brasileira, trazendo oportunidades aos empresários para realização de investimentos e lucros (Bresser-Pereira, 1985), nomeadamente para a indústria têxtil, de alimentos, de higiene e limpeza e de metalurgia.

A Constituição Brasileira de 1937, em seu artigo 129, mantendo o mesmo caráter assistencialista de outras medidas direcionadas à educação, previa a fundação de institutos de ensino por parte do Estado, direcionados para formação profissional e impunha como dever das indústrias e dos sindicatos, a criação de escolas aprendizes a jovens filhos de seus empregados ou de seus associados e, em seu texto, mostra o entrelaçamento ensino/indústria deixando clara a finalidade dos institutos de formação profissional que objetivavam o cumprimento, pela juventude, de seus deveres com a economia e a defesa da nação (Constituição de 1937, Art. $^{\circ}$ 132). Em 1938, o Ministério da Educação elaborou anteprojeto que regulamentava tal dispositivo e estipulava a criação das Escolas de Aprendizes Industriais que levariam os cidadãos a um convívio maior com as máquinas e com as novas tecnologias, introduzidas pela revolução industrial, trazendo enormes conversões na sociedade brasileira, constituindo-se um marco na história do progresso do País, ao passar a exigir uma formação com base no conhecimento e na reflexão.

Para atender as necessidades advindas da almejada industrialização, a mão-de-obra disponível precisava sofrer especializações de modo que a criação, em 1941, através do Decreto-Lei $\mathrm{n}^{\circ} 3.002$, de 30 de janeiro do mesmo ano, da Companhia Siderúrgica Nacional (CSN) no município de Volta Redonda, interior do estado do Rio de Janeiro, da criação da Companhia Vale Do Rio Doce, encampando as Companhias Brasileiras de Mineração e Siderurgia S.A. e Itabira de Mineração S.A., via Decreto Lei $n^{\circ} 4.352$, de $1^{\circ}$ de junho de 1942 na cidade do Rio de Janeiro e a criação, através do Decreto-Lei n ${ }^{\circ}$ 5.684, de 20 de julho de 1943 da Companhia Nacional de Álcalis, instalada em 1944, na cidade de Arraial do Cabo também no Estado do Rio de Janeiro, deixou explícita a necessidade de criação de operários que desenvolvessem as precisões das indústrias brasileiras que ao invés de exportar minério de ferro para importar trilhos de trens, passasse a produzir no Brasil estes mesmos artefatos.

Todavia, as especializações ainda padeciam do caráter de assistencialismo e de segregação impostos à população apta a entrar em escolas, pois continuava patente, como resquício do período colonial e imperial, deixar aos advindos de classes mais abastadas, os cursos de nível secundário, porta de entrada para o nível superior, e aos menos favorecidos, filhos de classe operária, os cursos industriais, agrícolas e comerciais que não permitiram o acesso ao ensino superior (Silveira, 2010).

Procurando a necessidade de se prosperar industrialmente, em 1942, através do Decreto 4048/42, foi criado o Serviço Nacional de Aprendizagem Industrial (SENAI), destinado à formação de trabalhadores com capacitação e qualificação para tender as demandas da indústria, cientes e convencidos de que sem aprendizado profissional não poderia haver crescimento industrial. Seguindo esta mesma vertente, alguns anos depois, em 1946, através do Decreto-Lei $\mathrm{N}^{\circ}$ 8.621 - de 10 de janeiro, é criado o Serviço Nacional de Aprendizagem Comercial (SENAC) destinado e voltado para o ensino profissional do setor do comércio de bens, serviços e turismo. Tendo a criação dos dois Serviços embutidos em si muito da virtude da maior visão dos empresários e investidores, onde o ensino brasileiro precisava suprir necessidades da economia e do desenvolvimento industrial do País, beneficiando ainda mais o crescimento da indústria local e a formação profissional de melhor qualidade e promovendo a oferta de mão-de-obra competente e talentosa para prover as demandas do parque industrial brasileiro que começava a crescer de forma acelerada com o fim da segunda Grande Guerra. Por outro lado, os países europeus se encontravam com a maioria de suas indústrias totalmente destruídas e precisavam, àquela altura, da importação de vários produtos de outros países, neles incluídos o Brasil.

As décadas seguintes, marcadas pela abertura ao capital internacional e incentivos à implantação de indústrias multinacionais, foram decisivas para a continuação e confirmação do desenvolvimento da indústria. E um novo desafio passou a fazer parte da estratégia brasileira para esse desenvolvimento: a reforma do sistema de educação técnica, superior e tecnológica que garantisse o aumento da oferta do ensino profissional e que estivesse em condições de competitividade com o padrão internacional. Mais clara ficou a visão de a tarefa preparatória para a qualificação dos trabalhadores para o mercado ser do sistema educacional, reforçando a relação educação/economia, evidenciada pela premência das empresas em ter trabalhadores com comprovada qualificação e, ao mesmo tempo, reconhecidos pelo sistema educacional.

As escolas, então, passaram a ser sinônimo de preparação para o mercado de trabalho redirecionando suas tarefas ao condicionamento das necessidades advindas das multifacetadas funções existentes no mercado empregador.

A existência das escolas públicas profissionalizantes, de forma explícita, vai ao encontro dos interesses do capital industrial, segundo o modelo vigente. Em decorrência do processo de mudança da sociedade, essas escolas vão se posicionando, de forma mais direta, vinculadas às políticas de desenvolvimento econômico estabelecido (MEC, 2010).

A partir daí, a função da escola como concebida na visão até então apregoada, tornou-se dividida e, assim, conceitualmente definidos tipos de escola, diferenciando-as conforme a origem de classe e a função destinada a elas na divisão social e técnica do trabalho.

Em 1961, através da Lei $n^{\circ} 4.024 / 61$ é autorizado o funcionamento de cursos em caráter experimental, na concepção de Cursos Superiores de Tecnologia, e cria os Cursos de Engenharia de Operações, em atendimento às demandas do setor produtivo. Mas, somente em 
1968, é criada a Lei Federal no 5.540/68 que implanta a reforma universitária, criando cursos profissionais de curta duração, que proporcionavam habilitações intermediárias de nível superior. Posteriormente, os cursos de engenharia de curta duração, viaram s ser extintos, em 1977, por decisão do governo federal. Dois anos após a Lei Federal 5.540/68, foi criada a primeira Faculdade de Tecnologia do Brasil, em Bauru São Paulo, sendo os Cursos Superiores de Tecnologia expandidos, até 1978, em número de 28 (SETEC/MEC 2011).

As escolas profissionalizantes, desta forma, passaram a constituir-se um suporte fundamental e estratégico para a indústria brasileira manter-se competitiva. As inovações tecnológicas, que implementadas e incorporadas constantemente às indústrias, fazem o mercado tornar-se cada vez mai, exigente e complexo, fazendo com que a educação profissional contribua de forma inequívoca para o crescimento industrial, indo de encontro aos seus interesses quando qualifica mão de obra, cria novas baias de crescimento econômico e, fundamentalmente, cria e aprofunda conhecimentos.

\section{A formação de professores para a educação profissional no Brasil}

A história mostra que - a formação de professores que atuam nos cursos da Educação Profissional e Tecnológica - a preocupação com o desempenho profissional sempre teve maior importância que a formação para a docência. A crença de que o conhecimento específico bastaria a quem quisesse ensinar, sobrepujou o preparo pedagógico do professor ou a qualidade didática de sua aula (Masetto, 1998). Mais tarde, com o modelo de Humboldt utilizado nas Universidades, o pedagógico continuou relegado à segundo plano, em nada acrescentando às necessidades formativas dos docentes.

$\mathrm{Na}$ educação profissional, os primeiros registros dessa deficiência datam de 1917, com a criação da Escola Normal de Arte de Ofícios Wenceslau Brás. Embora tenha formado, inicialmente, professores para trabalhos manuais e poucos para escolas profissionais, foi, sem dúvida, o primeiro passo para gerar atenção para a formação de docentes do segmento profissional.

Na década de 1930 e até a década de 1950, embora a necessidade de formação de mão-de-obra especializada de docentes para atender as universidades começasse a ser suprida, via cursos de pós- graduação, a formação pedagógica ainda estava longe de ter seus melhores desempenhos (Berbel, 1994) continuando desta maneira até a década de 1970, com características ainda pouco voltadas para o avanço pedagógico.

Algumas iniciativas tomadas pelo governo brasileiro foram sendo implantadas, mas todas sem muita consequência prática. Entre elas estão a Lei Orgânica do Ensino Industrial - Decreto Lei 4073/42 e a Portaria Ministerial 141/61, que definiu normas para registros de professores do ensino industrial e a aprovação do curso especial de educação técnica em cultura feminina, destinado a formar o magistério de economia doméstica e trabalhos manuais (MEC/SETEC, 2008).
A Lei de Diretrizes e Bases 4.024/61, em seu artigo 59, revogada mais tarde pela Lei $\mathrm{n}^{\circ}$ 5.692, de 1971, estabeleceu para formação de professores, cursos especiais de educação técnica - para disciplinas do ensino técnico- caminho este diferente para os que quisessem seguir o magistério do ensino médio, o que representou significativo avanço para a democratização do ensino, estabelecendo a articulação entre o ramo secundário e técnico e dando a devida equivalência, para fins de acesso, ao ensino superior. Mas também de pouca significância prática posto só ter sido regulamentada ao final da década de 1960.

Neste período, a Portaria Ministerial 141/61 foi elaborada como primeiro dispositivo para regulamentação dos cursos especiais aludidos na LDB 4.024/61, definindo sua aplicabilidade e objetivos, estabelecendo normas para registro do professor de ensino industrial, contemplando os diplomados em nível superior ou em nível técnico, quando em seus currículos estivessem explicitas disciplinas destinadas a lecionar.

Mais recentemente, a partir de 1997, o SENAI Serviço Nacional de Aprendizagem Industrial, no seu Centro de Formação, passou a ministrar o Programa Especial de Formação Pedagógica para Docentes da Educação Profissional em Nível Médio, tendo proporcionado formação pedagógica a engenheiros e outros profissionais que atuavam no próprio SENAI (Gatti, 2008).

Essas foram algumas das tentativas em determinar as atribuições e competências mínimas para o magistério, mas a falta de professores especializados com nível universitário acabou por deitar à terra todos os esforços neste sentido, sendo substituídos por simples exames de suficiência a serem aplicadas por instituições oficiais e de ensino superior. Esta carência de profissionais habilitados foi determinante para que o Ministério da Educação fosse autorizado a coordenar cursos superiores de formação de docentes para o ensino industrial.

\section{Considerações finais}

O processo de desenvolvimento profissional cria oportunidades de aprendizagem para o docente (Hargreves e Fullan, 1992) e encontra-se no topo das preocupações de como se obter-se e criar benefícios para a educação. Criar essas oportunidades é propiciar aos professores competências e conhecimentos que terminam por trazer condições mais vantajosas para o aprender dos alunos (Formosinho, 2009). Ainda segundo o autor, centrar o comportamento não levando em conta crenças, atitudes e comportamentos leva a uma "cegueira à realidade com várias consequências, entre elas a ineficácia" (p.231). O desenvolvimento profissional relexivo, segundo Sparks e Loucks-Horsley (1990), leva os docentes a pensar suas práticas potencializando suas competências e tornando seu desenvolvimento mais robusto.

A legislação promoveu a regulamentação da educação profissional, alterando a concepção de cursos técnicos e consolidando os cursos superiores de tecnologia, (MEC/SETEC, 2008), ao mesmo que se defrontava com 
a problemática que envolvia qualificação apropriada de professores para atuarem nos cursos técnicos e tecnológicos.

$\mathrm{Na}$ visão dos industriais, o ensino profissionalizante, seja ele de nível superior ou técnico, precisa atender às necessidades da economia e do desenvolvimento da indústria e, para isto, contam com a formação de profissionais que sejam formados em instituições especializadas, que os permitam atuarem com competência em seus postos de trabalho.

A situação de ausência de pessoal docente qualificado se constituiu num dos pontos nevrálgicos mais importantes que estrangulavam a expansão da educação profissional no Brasil, refletindo diretamente na qualidade e quantidade de mão de obra especializada, tão necessária ao desenvolvimento industrial.

A necessidade cada vez maior de crescimento da indústria brasileira e a procura mais acentuada por cursos técnicos e tecnológicos foram determinantes para que, em sua política educacional, o governo se preocupasse um pouco mais com a formação dos docentes que atuam nos centros de formação profissional, emitindo a Lei $\mathrm{n}^{\mathrm{o}}$. 11.741/2008 que redimensiona, institucionaliza e integra as ações da educação profissional técnica de nível médio, da educação de jovens e adultos e da educação profissional e tecnológica, determinando, ainda que este segmento da educação abrangerá os cursos de formação inicial e continuada ou qualificação profissional.

Diferentemente das Licenciaturas, a Educação Técnica e Tecnológica, dado a especificidade da área, requer uma formação pedagógica que ultrapasse a didática tradicional na tentativa de superar as deficiências da formação inicial e busque avançar para uma prática docente que venha de encontro às necessidades formativas dos profissionais docentes.

\section{Referências}

Berbel, N. N. (1994) Metodologia do ensino superior: realidade e significado. Campinas:Papirus.

Brasil, MEC/SETEC (2008). Diferenciais inovadores na formação de professores para a educação profissional. Revista Brasileira da Educação Profissional $e$ Tecnológica, 1,1 .

Brasil, MEC (2010). Instituto Federal de Educação, Ciência e Tecnologia. Um novo modelo em educação profissional e tecnológica: Concepção e diretrizes. Brasília.

Bresser-Pereira, L. C. (1985). Desenvolvimento e crise no Brasil 1930-1983. São Paulo: Ed. Brasiliense S.A.

Day, C. (2001). Desenvolvimento profissional de professores: Os desafios da aprendizagem permanente. Porto: Porto Editora.

Formosinho, J. O. (2009). Desenvolvimento profissional dos professores. In J. Formosinho. Formação de Professores: Aprendizagem profissional e acção docente (pp. 221-284). Porto: Porto Editora.

Furtado, C. (1997). Formação econômica do Brasil (26a . ed.). São Paulo: Nacional.
Gatti, B. A. (2008). Análise das políticas para formação continuada no Brasil, na última década. Revista Brasileira de Educação, 13(37), 57-69.

Huberman, M. (1992). O ciclo de vida profissional dos professores. In A. Nóvoa (Ed.), Vidas de professores. Colecção Ciências da Educação (pp.31-65). Porto: Porto Editora.

Kugel, P. (1993). How professors develop as teachers. Studies in Higher Education, 18, 315-329.

Leithwood, K.A. (1990). The principal's role in teacher development. In B. Joyce (Ed.), Changing school culture through staff development (pp.71-90). USA: ASCD.

Masetto, M. (Org.), (1998). Docência na Universidade. Campinas: Papirus.

Pinheiro, A. M., Pinheiro M. D. B., Barreira, C. F., \& Vaz-Rebelo, M. P. (2015). Formação pedagógica de professores da educação profissional e tecnológica numa instituição Brasileira. Revista de Estudios $e$ Investigación en Psicología y Educación, Vol. Extr 6, 116-120.

Robertson, D. (1999). Professors' perspectives on their teaching: A new construct and developmental model. Innovative Higher Education. Georgia: Universidade da Georgia.

Sikes, P. (1992). The life cycle of the teacher. In S. Ball \& I. Goodson (Eds.), Teachers' lives and careers (pp.27-60). Philadelphia: Falmer Press.

Sparks, D., \& Loucks-Horlsley, S. (1990). Models of satff development. In W. R. Houston (Ed.). Handbook of research on teacher education (pp. 234-251). New York: MacMillan.

Steffy, B. E., Wolfe, M. P., Pash, S. H., \& Enz, B. J. (2000). The life cycle of the teacher career. California: Corwin Press.

Zabalza, M. A. (2007). O ensino universitário: Seu cenário e seus protagonistas. Porto Alegre: Artmed.

Zabalza, M. A. (2007). Competências docentes del profesorado Universitario: Calidad y desarrollo profesional. Madrid: Narcea. 